\title{
Electrochemical supercapacitor with polymeric active electrolyte $\uparrow$
}

Cite this: J. Mater. Chem. A, 2014, 2 , 10526

\author{
Received 18th March 2014 \\ Accepted 6th May 2014 \\ DOI: $10.1039 / \mathrm{c} 4 \mathrm{ta0} 1319 \mathrm{k}$ \\ www.rsc.org/MaterialsA
}

\begin{abstract}
Libin Chen, Yanru Chen, Jifeng Wu, Jianwei Wang, Hua Bai* and Lei Li*
An electrochemical supercapacitor with a polymeric active electrolyte was designed and fabricated in this work. A water-soluble conducting polymer, sulfonated polyaniline (SPAni), was used in the supercapacitor as the active electrolyte and a semipermeable membrane was employed as the separator of the device. It was found that SPAni in the electrolyte can provide pseudocapacitance via its reversible electrochemical redox reaction. Owing to the good stability of SPAni, the supercapacitor has a long cycling life. Moreover, the migration of SPAni between the two electrodes was blocked by the semipermeable membrane separator, thus self-discharge caused by the shuttle effect of SPAni was suppressed. The research in this paper demonstrates the possibility of using a polymer as the active electrolyte in a supercapacitor and has paved a new way to achieve active electrolyte enhanced supercapacitors with high capacitance and good energy retention.
\end{abstract}

\section{Introduction}

Electrochemical supercapacitors (ESCs) are storage devices for electric energy, which possess much higher power density compared with batteries. Therefore, ESCs are important for applications that require a large current supply such as electrical vehicles. ${ }^{1,2}$ Two basic types of ESCs are commonly described in the literature depending on the mechanism of energy storage: electrochemical double layer supercapacitors (EDLSCs), in which the energy is stored by ion adsorption on the surface of the electrodes, ${ }^{3-5}$ and pseudocapacitors, in which fast surface redox reactions are employed to store energy. ${ }^{1}$ Pseudocapacitors usually have a higher specific capacitance than EDLSCs; thus, they have received considerable attention in recent years. ${ }^{6-8}$ The surface redox reactions in pseudocapacitors can be achieved by modifying the electrode with electroactive materials or using soluble redox active electrolytes. The incorporation of redox active species in the electrolyte solution, compared with modification of the electrode with redox materials, is much easier to carry out and is compatible with the current fabrication technology of supercapacitors. Recently, various redox active small molecules or ions, including hydroquinone (HQ) ${ }^{9-12}$ ferricyanide $\left(\mathrm{Fe}(\mathrm{CN})_{6}{ }^{4-}\right),{ }^{13,14}$ iodide $\left(\mathrm{I}^{-}\right),{ }^{15}$ methylene blue, ${ }^{16}$ and phenylenediamine, ${ }^{17,18}$ have been used in supercapacitors to achieve high pseudocapacitance (active electrolyte enhanced supercapacitor, AEESC). The specific capacitance $\left(C_{\mathrm{s}}\right)$ values were greatly improved after the addition

College of Materials, Xiamen University, Xiamen, 361005, P. R. China. E-mail: baihua@xmu.edu.cn; lilei@xmu.edu.cn

$\dagger$ Electronic supplementary information (ESI) available: Characterization of SPAni, repeatability of the devices, AC impedance spectrum of device 2, and other additional data. See DOI: 10.1039/c4ta01319k of the redox electrolytes. For example, Ricardo et al. successfully increased the $C_{\mathrm{s}}$ of carbon-based ESCs from $\sim 320 \mathrm{~F} \mathrm{~g}^{-1}$ to $901 \mathrm{~F}$ $\mathrm{g}^{-1}$ using the redox active electrolyte HQ. ${ }^{10}$

Although redox electrolytes can significantly increase the $C_{\mathrm{s}}$ of ESCs, they also bring a serious problem of fast self-discharge (SDC). We found along with other groups that the SDC process was obviously accelerated after active electrolytes were incorporated into the ESCs. ${ }^{15,19,20}$ The SDC rate is an index of energy retention of an ESC, and fast SDC will strongly limit the practical applications of the ESC. As demonstrated in our previous report, the fast SDC of an AEESC is caused by the shuttle effect of the active electrolyte. The electrolysis products of the active species generated on one electrode diffuses to another electrode, where they deplete the charges stored on the electrode by an inverse electrochemical reaction. ${ }^{20}$ Therefore, in order to suppress the fast SDC of an AEESC, the shuttle of the active electrolyte between the two electrodes must be blocked. ${ }^{19,20}$ The shuttle of small molecule active electrolytes between two electrodes can be stopped in two ways. One strategy is to choose a special active electrolyte. As we reported, no shuttle effect was found when $\mathrm{Cu}^{2+}$ was used as the active electrolyte; $\mathrm{Cu}^{2+}$ was converted into insoluble $\mathrm{Cu}$ and deposited onto the electrode during charge process. ${ }^{20}$ Therefore, there will be no migration of the electrochemical product. Another strategy is to use an ionexchange membrane as the separator of the device, which can block the migration of the active electrolyte. ${ }^{19}$ However, an anion-exchange membrane separator is expensive, increasing the cost of ESCs and limiting their practical application.

Herein, we have designed a new type of AEESC based on a polymeric active electrolyte and a volume-selective semipermeable separator (polymeric active electrolyte enhanced supercapacitor, PAEESC). The semipermeable membrane can block 
the diffusion of a bulky polymeric active electrolyte but allows free migration of small ions. Consequently, the SDC caused by the shuttle effect was suppressed efficiently. A commonly-used regenerated cellulose dialysis tube with a molecular weight cutoff (MWCO) of 8000-14 000 was employed as the separator, and sulfonated polyaniline (SPAni) as the polymeric active electrolyte. SPAni has a good redox activity and stability, is easy to synthesize and is commercially available. Because of the use of a polymeric redox active electrolyte and semipermeable membrane, the $C_{\mathrm{s}}$ of the ESC device was improved without the obvious degradation of energy retention.

\section{Experimental}

\section{Materials}

Concentrated sulfuric acid (98\%), sodium nitrate, hydrochloric acid and hydrazine hydrate (80\%) were purchased from Xilong Chemical Industry Incorporated Co. Ltd. Potassium permanganate, hydrogen peroxide (30\%), aniline, ammonium persulfate, chlorosulfonic acid and hydroquinone were bought from Sinopharm Chemical Reagent Co., Ltd. SPAni was synthesized in our lab following the previously reported procedures (see Fig. S1-S3† for the spectral data of SPAni). ${ }^{21,22}$ Graphene oxide (GO) was prepared from natural graphite (325 mesh, Qingdao) according to the modified Hummers' method. ${ }^{23,24}$ Dialysis tube with a MWCO of 8000-14 000 is the product of Viskase.

\section{Assembly of the supercapacitor device}

A two-electrode device configuration was used in this work, and graphene hydrogel (GHG) was chosen as the electrode. GHG was prepared by the hydrothermal reduction of GO and further treated with hydrazine, according to the method reported by Zhang et al. (Fig. S4 $\dagger$ ). ${ }^{25}$ Before assembly of the device, the GHG blocks were compressed to thin discs (diameter $\sim 8 \mathrm{~mm}$, thickness $\sim 1.5 \mathrm{~mm})$. Two pieces of Pt foil $\left(2 \times 2 \mathrm{~cm}^{2}\right)$ were used as current collectors. To seal the device, a silicone ring was sandwiched between the Pt foils, with graphene gel, separator, and electrolyte solution accommodated within it. The electrolyte solution was $0.1 \mathrm{M}$ SPAni $+4 \mathrm{M} \mathrm{H}_{2} \mathrm{SO}_{4}$ (device 2). For comparison, devices with $4 \mathrm{M} \mathrm{H}_{2} \mathrm{SO}_{4}$ (device 1) or $0.1 \mathrm{M} \mathrm{HQ}+4$ $\mathrm{M} \mathrm{H}_{2} \mathrm{SO}_{4}$ (device 3 ) as the electrolyte were also assembled. To investigate the electrode process of a single electrode, a threeelectrode cell was used. The abovementioned two-electrode device was immersed into an electrochemical cell filled with the same electrolyte as used in the device. Two openings were cut on the silicon rubber gasket to ensure the connectivity of the electrolyte in the device and the cell. The two electrodes of the device were used as working and counter electrode, and a saturated calomel electrode (SCE) was utilized as the reference electrode.

\section{Measurements}

The morphologies of GHG and the separator were observed using a scanning electron microscope (SEM, LEO1530) operated at $20 \mathrm{kV}$. All the electrochemical measurements were conducted using a CHI 660 electrochemical workstation. A three-electrode system was used to investigate the electrochemical properties of SPAni, in which a glassy carbon (GC, $\phi=3 \mathrm{~mm}$ ) or GHG modified GC electrode was employed as working electrode, a platinum foil $(1 \mathrm{~cm} \times 1 \mathrm{~cm})$ and a SCE as the counter and reference electrodes, respectively. The ESC devices were tested by cyclic voltammetry (CV), galvanostatic charge-discharge (GCD) and AC impedance. The $C_{\mathrm{s}}$ of the device was calculated according to the following equations:

$$
\begin{gathered}
C_{\mathrm{s}}=\frac{J t}{V-\mathrm{IR}}, \\
J=\frac{I}{m},
\end{gathered}
$$

where $J$ is the mass current density, $I$ the current applied on the device, $t$ the discharge time, $m$ the total mass of the two electrodes, $V$ the highest voltage in the GCD curves and IR represents the voltage drop at the beginning of the discharge process. The specific capacitance of a single electrode was calculated from the potential curves measured with the three-electrode system:

$$
\begin{aligned}
C_{+} \text {or } C_{-} & =\frac{J t}{\Delta V-\mathrm{IR}}, \\
J & =\frac{I}{m},
\end{aligned}
$$

where $m$ is the mass of a single electrode and $\Delta V$ the potential change of the electrode during the discharge process; $I, t$ and IR have the same definitions as in eqn (1) and (2).

\section{Results and discussion}

Fig. 1 represents the $\mathrm{CV}$ and GCD curves of the ESCs with $\mathrm{H}_{2} \mathrm{SO}_{4}$ (device 1) and SPAni- $\mathrm{H}_{2} \mathrm{SO}_{4}$ (device 2) as the electrolyte, respectively. The $\mathrm{CV}$ curves of device 1 (Fig. 1A) are nearly rectangular with a pair of weak redox waves, which are attributed to the redox reaction of the oxygen-containing groups on chemically reduced graphene (CCG). ${ }^{26}$ The current density in the $\mathrm{CV}$ curves is proportional to the scan rate (Fig. S5†), indicating that the electrode process is not controlled by diffusion. ${ }^{27}$ Such a linear relationship between the current density and scan rate is the characteristic of a capacitor. The GCD curves of device 1 are shown in Fig. 1B, which have a triangular shape. The $C_{\mathrm{s}}$ of device 1 was calculated from the GCD curves according to eqn (1). At a current density of $0.88 \mathrm{~A} \mathrm{~g}^{-1}$, the $C_{\mathrm{s}}$ of device 1 is $52.5 \mathrm{~F} \mathrm{~g}^{-1}$ and decreases slightly to $47.5 \mathrm{~F} \mathrm{~g}^{-1}$ when the current density rises to $4.42 \mathrm{~A} \mathrm{~g}^{-1}$. These values agree well with the reported results $\left(C_{\mathrm{s}}\right.$ of a single electrode reported by Zhang et al. was $205 \mathrm{~F} \mathrm{~g}^{-1}$ at $1 \mathrm{~A} \mathrm{~g}^{-1}$, corresponding to a $C_{\mathrm{s}}$ of a device of $51.2 \mathrm{~F} \mathrm{~g}^{-1}$ at $\left.0.5 \mathrm{~A} \mathrm{~g}^{-1}\right),{ }^{25}$ demonstrating good performance of our GHG electrodes.

The CV and GCD curves of device 2 are shown in Fig. 1C and D. Compared with device 1 , the CV curves (Fig. 1C) of device 2 have a larger current density but their shapes are still deformed rectangles. The current density in these CV curves is also proportional to the scan rate, showing the characteristic CV behavior of an ideal capacitor (Fig. S6†). The GCD curves shown 

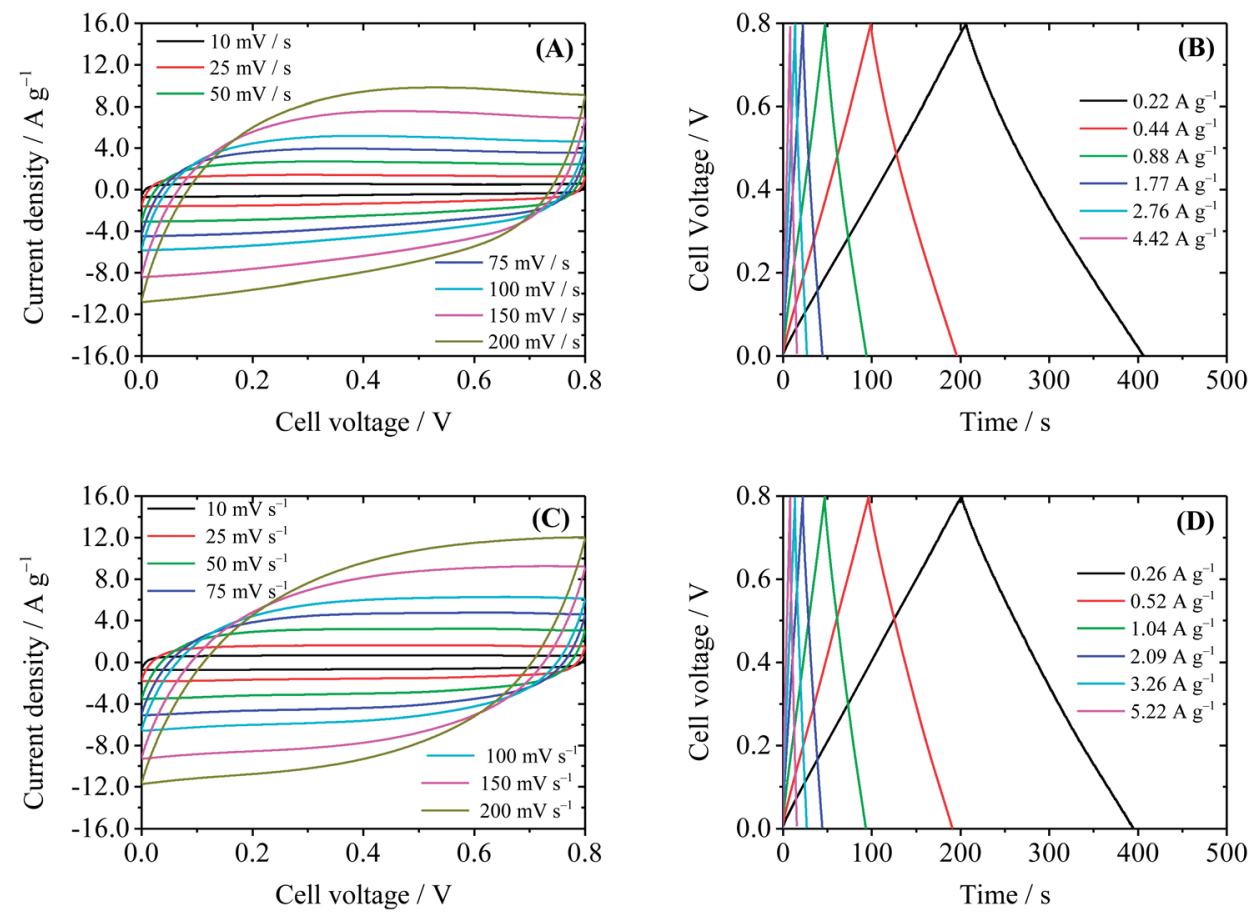

Fig. 1 Performance of device $1\left(4 \mathrm{M} \mathrm{H}_{2} \mathrm{SO}_{4}\right)$ and device 2 (0.1 M SPAni $+4 \mathrm{M} \mathrm{H}_{2} \mathrm{SO}_{4}$, with semipermeable membrane as separator). (A) and (B) CV and GCD curves of device 1. (C) and (D) CV and GCD curves of device 2.

in Fig. 1D are nearly triangular, which correspond with the CV curves. The $C_{\mathrm{s}}$ values of device 2 calculated from the GCD curves are represented in Fig. 2. A $C_{\mathrm{s}}$ value of $57 \mathrm{~F} \mathrm{~g}^{-1}$ at $5.22 \mathrm{~A} \mathrm{~g}^{-1}$ was obtained for device 2 , which is $20 \%$ higher than that of device 1 . When the current density increases from 0.26 to $5.22 \mathrm{~A} \mathrm{~g}^{-1}$, the $C_{\mathrm{s}}$ value of device 2 only decreases by $10.6 \%$, showing a good rate performance (for device 1 , when the current density increases from 0.22 to $4.42 \mathrm{~A} \mathrm{~g}^{-1}$, the $C_{\mathrm{s}}$ value decreases by $14.4 \%$ ). The cycling stability of device 2 was also studied by GCD at a constant current density of $1.04 \mathrm{~A} \mathrm{~g}^{-1}$. As shown in Fig. 3, the $C_{\mathrm{s}}$ of device 2 remains $99 \%$ after 1000 cycles. The stability of the capacitor is sufficient for practical application. In fact, polyaniline and its derivatives usually have good electrochemical stability. Moreover, the electrochemical reactions of

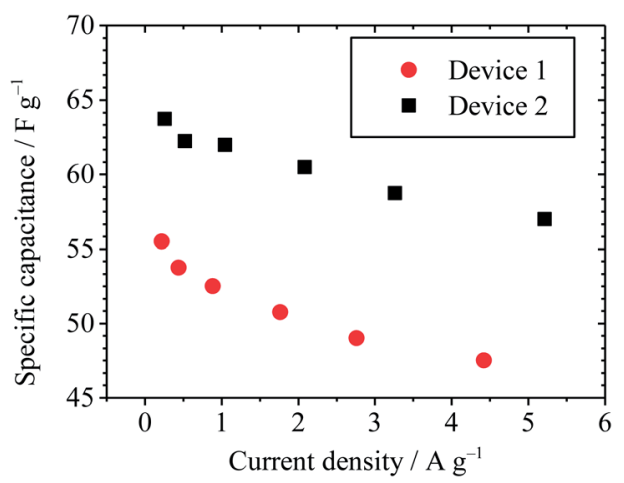

Fig. 2 Specific capacitance of device $1\left(4 \mathrm{M} \mathrm{H}_{2} \mathrm{SO}_{4}\right)$ and device 2 (0.1 $\mathrm{MSPAni}+4 \mathrm{M} \mathrm{H}_{2} \mathrm{SO}_{4}$, with semipermeable membrane as separator) at different current densities.

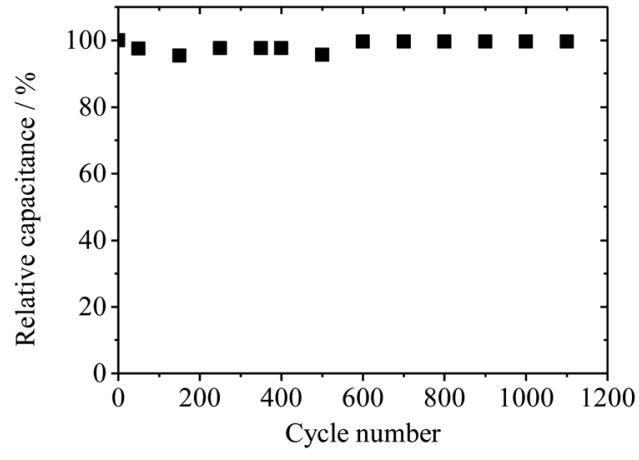

Fig. 3 Cycling stability of device 2 (0.1 M SPAni $+4 \mathrm{M} \mathrm{H}_{2} \mathrm{SO}_{4}$, with semipermeable membrane as separator) upon GCD at a current density of $1.04 \mathrm{~A} \mathrm{~g}^{-1}$.

SPAni take place in the electrolyte, thus during chargedischarge cycles, there will be no obvious change in the volume of the electrodes. In many devices, the repeating volume change of the electrodes, caused by the electrochemical reaction of the electroactive materials in the electrodes, will damage the good electric contact between the electrode and current collector, leading to the degradation of the device performance. ${ }^{28}$ Therefore, stable active materials and suitable device structure endue device 2 with good cycle stability.

To elucidate the working mechanism of the SPAni-containing AEESC, the electrochemical properties of SPAni was investigated. Fig. 4 depicts the $\mathrm{CV}$ curves of $\mathrm{GC}$ and GHG modified GC electrodes in a $4 \mathrm{M} \mathrm{H}_{2} \mathrm{SO}_{4}$ or $0.1 \mathrm{M}$ SPAni $+4 \mathrm{M} \mathrm{H}_{2} \mathrm{SO}_{4}$ solution. In $\mathrm{H}_{2} \mathrm{SO}_{4}$, the $\mathrm{CV}$ curve of the GHG modified GC 


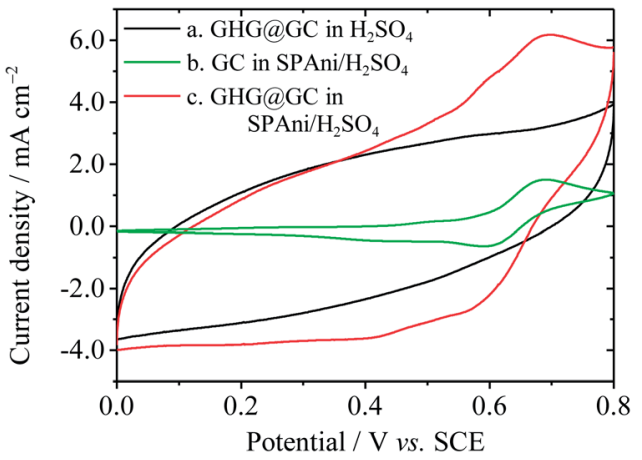

Fig. $4 \mathrm{CV}$ curves of $\mathrm{H}_{2} \mathrm{SO}_{4}$ or SPAni- $\mathrm{H}_{2} \mathrm{SO}_{4}$ on different electrodes at a scan rate of $25 \mathrm{mV} \mathrm{s}^{-1}$.

electrode (curve a) is a tilt rectangle, showing a large EDL capacitance. A pair of wide redox waves at $\sim 0.3 \mathrm{~V}$ is found in the $\mathrm{CV}$ curve, which is related to the residual oxygen-containing functional groups on the CCG sheets. The CV curve of the bare GC electrode in SPAni- $\mathrm{H}_{2} \mathrm{SO}_{4}$ solution (curve b) shows a much lower charging current due to the smaller surface area of the GC electrode. There are two pairs of redox waves in this CV curve, a small pair at $0.45 \mathrm{~V} v s$. SCE and a large pair at $0.65 \mathrm{~V} v s$. SCE. These waves can be attributed to the transition of the polyaniline backbone between its different doping states, namely from leucoemeraldine to emeraldine $(0.45 \mathrm{~V})$ and from emeraldine to pernigraniline $(0.65 \mathrm{~V})$, as illustrated in Scheme $1 .^{29,30}$ The $\mathrm{CV}$ curve of GHG in a SPAni- $\mathrm{H}_{2} \mathrm{SO}_{4}$ solution (curve c) is the superposition of curve a and $b$. The oxidization peak of SPAni at $0.65 \mathrm{~V} v s$. SCE is also found in curve $\mathrm{c}$, indicating that the electrochemical oxidation processes of SPAni on GHG and GC<smiles>Cc1ccc(Nc2ccc(Nc3ccc(Nc4ccc(N)c(S(=O)(=O)O)c4)c(S(=O)(=O)O)c3)c(S(=O)(=O)O)c2)c(S(=O)(=O)O)c1</smiles>

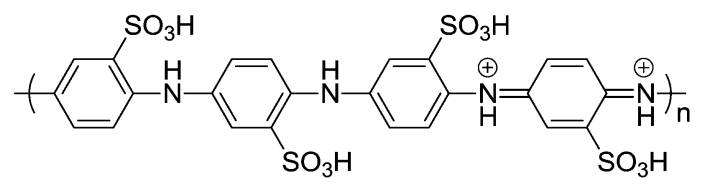

emeraldine salt

$$
+2 \mathrm{e}-\|,-2 \mathrm{e}-
$$

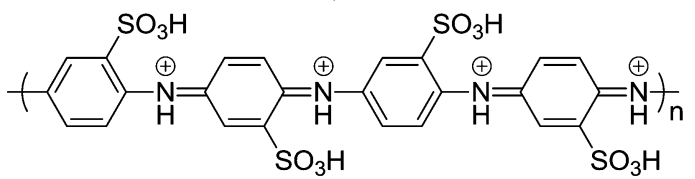

pernigraniline salt

Scheme 1 Reversible redox reactions of SPAni in an acidic medium. are identical. The peak current in curve $\mathrm{c}$ is larger than that in curve $b$ due to large electrode surface area. Therefore, from the CV study it is concluded that SPAni is able to provide pseudocapacitance when the electrode potential is above $0.45 \mathrm{~V} v s$. SCE.

The electrode process of each electrode in device 2 during GCD was investigated in a three-electrode configuration system. In such a configuration, the variation of the potential of each electrode can be monitored. Fig. 5 shows the evolution of the cell voltage and the potential of each electrode during the GCD process. From Fig. 5, it is easy to conclude that device 2 is an asymmetric supercapacitor. The equilibrium potential of both the electrodes is $\sim 0.4 \mathrm{~V} v$ s. SCE. This is determined by the equilibrium potential of the reaction from leucoemeraldine to emeraldine. When the supercapacitor is charged, the potential of the anode increases from 0.4 to $0.6 \mathrm{~V} v s$. SCE, while that of the cathode decreases from 0.4 to $-0.2 \mathrm{~V} v$ s. SCE. In the potential range of -0.2 to $0.4 \mathrm{~V} v$ s. SCE, there is no redox reaction related to SPAni, as demonstrated by the CV curves in Fig. 4 . Thus, the capacitance of the cathode is mainly EDL capacitance (Scheme 2). The small plateau in the potential curve of the cathode at a potential of $-0.2 \mathrm{~V} v s$. SCE is caused by the decomposition of water. ${ }^{20,31}$ The $C_{\mathrm{s}}$ of the cathode is calculated to be $190 \mathrm{~F} \mathrm{~g}^{-1}$ which agrees with the reported data. ${ }^{25}$ However, for the anode, its potential changes are much slower when compared with that of the cathode in the GCD process, indicating a larger anode capacitance. The specific capacitance of the anode is $361 \mathrm{~F} \mathrm{~g}^{-1}$ according to the potential curve in Fig. 5 . Since the capacitance of the device is the series capacitance of two electrodes, it will be

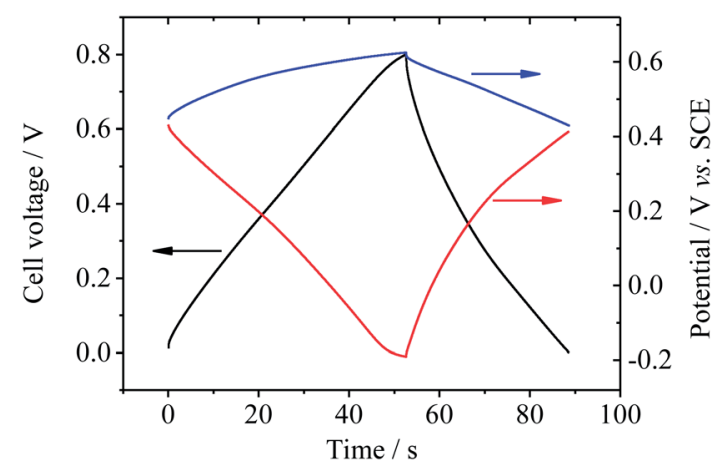

Fig. 5 Potential curves of a single electrode of device 2 (0.1 M SPAni + $4 \mathrm{M} \mathrm{H}_{2} \mathrm{SO}_{4}$, with semipermeable membrane as separator) during GCD. Current density: anode, $3.07 \mathrm{~A} \mathrm{~g}^{-1}$; cathode, $2.71 \mathrm{~A} \mathrm{~g}^{-1}$.

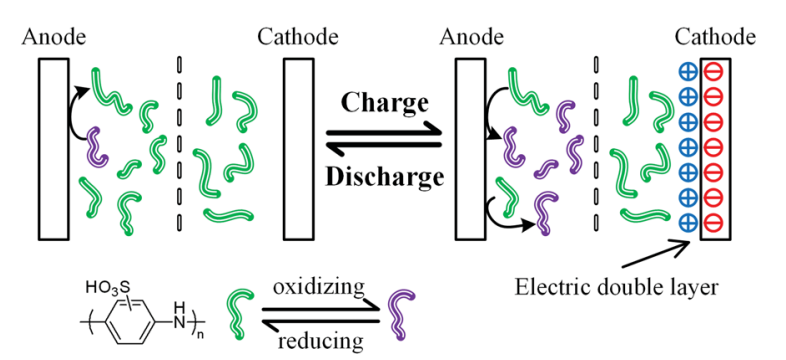

Scheme 2 Working mechanism of device 2 (0.1 M SPAni $+4 \mathrm{M} \mathrm{H}_{2} \mathrm{SO}_{4}$, with a semipermeable membrane as separator). 
enhanced by the large capacitance of the anode. These results are similar with those reported for AEESCs based on small active molecules or ions. ${ }^{9}$ As depicted in Scheme 2 , in the charge process, the anode current is consumed by the SPAni molecules, which are oxidized from leucoemeraldine to emeraldine and pernigraniline. Therefore, only a small portion of the current is utilized to charge the EDL of the anode, leading to a small potential shift (depolarization of SPAni) and a large apparent capacitance. In other words, on the anode the charges are stored in the SPAni molecules rather than in the EDL. In the discharge process, pernigraniline undergoes a reverse reduction reaction, releases the stored charge and returns to leucoemeraldine. Therefore, in the anode chamber the electric energy is stored in oxidized SPAni molecules in the electrolyte solution but in the cathode chamber it is stored on the surface of the electrode (in EDL). We also investigated the influence of SPAni concentration on the performance of the device. It was found that in the range of $0.02-0.1 \mathrm{M}$, the concentration of SPAni has little effect on the $C_{\mathrm{S}}$ of the device (see Fig. S7†). This result demonstrates that at these concentrations there is always sufficient SPAni on the surface of the anode during the charge process, even the depletion effect of SPAni caused by constantcurrent electrolysis is considered. It should be noted that an asymmetric device structure with a small anode mass and large cathode mass can further improve the specific capacitance of device 2 by balancing the capacitances of the two electrodes.

In a charged device, if the oxidized SPAni molecules can penetrate through the separator, they will come into contact with the cathode, whose potential is lower than their equilibrium potential. Thus, these molecules will be reduced by the cathode causing SDC. Such a SDC process is commonly found in AEESC. Therefore, in device 2, we used a size-selective semipermeable membrane (dialysis tube) as the separator to block the shuttle of SPAni between the two electrodes. In our dialysis experiment, after $48 \mathrm{~h}$, no SPAni was detected by UV-Vis spectroscopy in the diffusate; thus, the dialysis tube with a MWCO of 8000-14000 can efficiently block the diffusion of SPAni. Fig. 6 compares the SDC rate of device 1 and device 2 . Device 1 as a pure EDLSC was used as the reference whose SDC process is considered to be governed by ion diffusion. ${ }^{32,33}$ If the SDC rate of device 2 is not larger than that of device 1 , it can be concluded that SPAni does not accelerate the SDC process. To demonstrate the importance of the semipermeable membrane separator, the SDC curve of another device, which was identical to device 2 with the exception that the separator was replaced by a porous cellulose acetate membrane (pore size: $220 \mathrm{~nm}$, Fig. S12 $\dagger$ ), was also measured (device 3). All the devices were charged to $0.8 \mathrm{~V}$ and then their open circuit voltages were recorded. As shown in Fig. 6, device 2 and device 1 have similar SDC rates. After $10000 \mathrm{~s}$, the voltage of device 2 is $0.38 \mathrm{~V}$, only $0.01 \mathrm{~V}$ lower than that of device 1 . After $18000 \mathrm{~s}$, the cell voltage of device 2 becomes even larger than that of device 1. As a comparison, in $10000 \mathrm{~s}$ the cell voltage of device 3 dwindles down to $0.23 \mathrm{~V}$, which is much lower than device 2. These results clearly demonstrate that the semipermeable membrane successfully blocks the migration of SPAni between the anode and cathode chambers, thus suppressing the SDC. In another

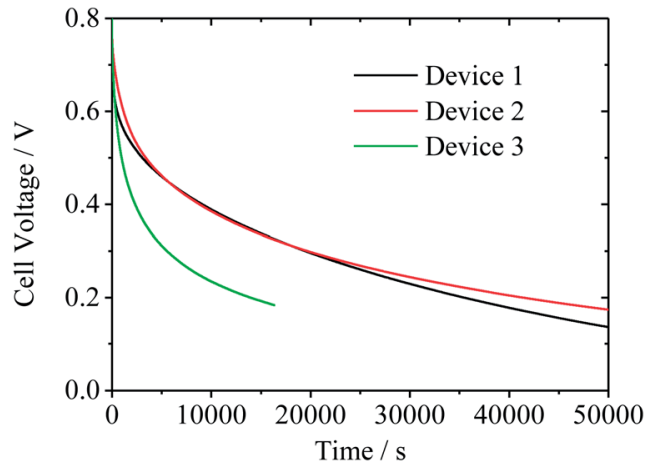

Fig. 6 Self-discharge curves of device $1\left(4 \mathrm{M} \mathrm{H}_{2} \mathrm{SO}_{4}\right)$, device $2(0.1 \mathrm{M}$ SPAni $+4 \mathrm{M} \mathrm{H}_{2} \mathrm{SO}_{4}$, with semipermeable membrane as separator) and device 3 (0.1 M SPAni $+4 \mathrm{M} \mathrm{H}_{2} \mathrm{SO}_{4}$, with porous cellulose acetate membrane as separator).

control experiment, we fabricated another device, in which the active electrolyte SPAni in device 2 was replaced with HQ, a small molecule (device 4). Because HQ can pass through the semipermeable membrane, the SDC rate of device 4 is obviously larger than device 2 (Fig. S13†). Therefore, in order to suppress the fast SDC process, both the polymeric active electrolyte with large molecular mass and size-selective semipermeable membrane are necessary for this type of device.

\section{Conclusion}

In conclusion, we have designed a novel type of supercapacitor (PAEESC) with electroactive polymers as the additive in the electrolyte and a semipermeable membrane as the separator. A PAEESC with SPAni as the polymeric active electrolyte was fabricated. Owing to the pseudocapacitance provided by SPAni, the specific capacitance of the device was improved when compared with the corresponding EDLSC. Furthermore, using a semipermeable dialysis membrane as the separator, the migration of SPAni between the anode and cathode was blocked, thus the SDC process of the device was successfully suppressed. This research opens a new way to AEESCs with both high capacitance and good energy retention. We believe that PAEESC is a promising type of supercapacitor and its performance can be further improved in the future by designing advanced polymeric active electrolytes.

\section{Acknowledgements}

The authors thank the National Natural Science Foundation of China (21104041) for financial support.

\section{Notes and references}

1 B. E. Conway, Electrochemical Supercapacitors: Scientific Fundamentals and Technological Applications, Kluwer Academic/Plenum Publishers, New York, 1999.

2 M. S. Whittingham, Proc. IEEE, 2012, 100, 1518-1534.

3 E. Frackowiak and F. Béguin, Carbon, 2001, 39, 937-950. 
4 L. L. Zhang and X. S. Zhao, Chem. Soc. Rev., 2009, 38, 25202531.

5 M. Inagaki, H. Konno and O. Tanaike, J. Power Sources, 2010, 195, 7880-7903.

6 J. F. Mike and J. L. Lutkenhaus, ACS Macro Lett., 2013, 2, 839844.

7 C. D. Lokhande, D. P. Dubal and O. S. Joo, Curr. Appl. Phys., 2011, 11, 255-270.

8 G. A. Snook, P. Kao and A. S. Best, J. Power Sources, 2011, 196, 1-12.

9 S. Roldán, M. Granda, R. Menéndez, R. Santamaría and C. J. Blanco, Phys. Chem. C, 2011, 115, 17606-17611.

10 S. Roldán, C. Blanco, M. Granda, R. Menéndez and R. Santamaría, Angew. Chem., Int. Ed., 2011, 50, 1699-1701.

11 S. T. Senthilkumar, R. K. Selvan, N. Ponpandian and J. S. Melo, RSC Adv., 2012, 2, 8937-8940.

12 W. Chen, R. B. Rakhi and H. N. Alshareef, Nanoscale, 2013, 5, 4134-4138.

13 L. H. Su, X. G. Zhang, C. H. Mi, B. Gao and Y. Liu, Phys. Chem. Chem. Phys., 2009, 11, 2195-2202.

14 Y. Tian, J. Yan, R. Xue and B. J. Yi, J. Electrochem. Soc., 2011, 158, A818-A821.

15 S. T. Senthilkumar, R. K. Selvan, Y. S. Lee and J. S. Melo, J. Mater. Chem. A, 2013, 1, 1086-1095.

16 S. Roldán, M. Granda, R. Menéndez, R. Santamaría and C. Blanco, Electrochim. Acta, 2012, 83, 241-246.

17 H. Yu, L. Fan, J. Wu, Y. Lin, M. Huang, J. Lin and Z. Lan, RSC Adv., 2012, 2, 6736-6740.

18 H. Yu, J. Wu, L. Fan, Y. Lin, S. Chen, Y. Chen, J. Wang, M. Huang, J. Lin, Z. Lan and Y. Huang, Sci. China: Chem., 2012, 55, 1319-1324.
19 M. Tachibana, T. Ohishi, Y. Tsukada, A. Kitajima, H. Yamagishi and M. Murakami, Electrochemistry, 2011, 79, 882-886.

20 L. B. Chen, H. Bai, Z. F. Huang and L. Li, Energy Environ. Sci., 2014, 7, 1750.

21 S. Ito, K. Murata, S. Teshima, R. Aizawa, Y. Asako, K. Takahashi and B. M. Hoffman, Synth. Met., 1998, 96, 161-163.

22 H. Bai, Y. X. Xu, L. Zhao, C. Li and G. Q. Shi, Chem. Commun., 2009, 1667-1669.

23 W. S. Hummers and R. E. Offeman, Chem. Soc., 1958, 80, 1339.

24 Y. Q. Chen, K. W. Chen, H. Bai and L. Li, J. Mater. Chem., 2012, 22, 17800-17804.

25 L. Zhang and G. Q. Shi, J. Phys. Chem. C, 2011, 115, 1720617212.

26 K. X. Sheng, Y. X. Xu, C. Li and G. Q. Shi, New Carbon Mater., 2011, 26, 9-15.

27 A. J. Bard and L. R. Faulkner, Electrochemical methods: Fundamentals and applications, John Wiley \& Sons, New York, 2nd edn, 2001.

28 S. M. Paek, E. Yoo and I. Honma, Nano Lett., 2008, 9, 72-75.

29 J. Yue, Z. H. Wang, K. R. Cromack and A. J. Epstein, J. Am. Chem. Soc., 1991, 113, 2665-2671.

30 E. T. Kang, K. G. Neoh and K. L. Tan, Prog. Polym. Sci., 1998, 23, 277-324.

31 S. Ban, J. Zhang, L. Zhang, K. Tsay, D. Song and X. Zou, Electrochim. Acta, 2013, 90, 542-549.

32 B. E. Conway, W. G. Pell and T. C. Liu, J. Power Sources, 1997, 65, 53-59.

33 B. W. Ricketts and C. Ton-That, J. Power Sources, 2000, 89, 64-69. 